\title{
ORIGINAL ARTICLE \\ Reproducibility and responsiveness of heart rate indexes to assess wheeling efficiency in patients with spinal cord injuries
}

\author{
FR Neto, ACB Coutinho and PSS Beraldo
}

\section{Study design: Cross-sectional study.}

Objectives: To measure the reproducibility and responsiveness of heart rate indexes in measuring energy expenditure during wheelchair locomotion of adults with spinal cord injury (SCI).

Setting: SARAH Rehabilitation Hospital Network-Brasilia, Brazil.

Methods: The study consecutively enrolled 35 individuals with SCl. Volunteers propelled their wheelchairs at a self-selected and comfortable velocity around a circular track. The first assessment day was a responsiveness study, in which three tests were performed, with the wheelchair weight increased randomly during the last two tests. On the second assessment day, the test was conducted without extra weight (that is, baseline conditions) for reproducibility analyses.

Results: All indexes demonstrated reproducibility on all statistical analyses. The Propulsion Cardiac Cost Index (PCCI) had a lower variation coefficient than the Physiological Cost Index ( $\mathrm{PCl} ; 8.5 \%$, 95\% confidence interval $(\mathrm{Cl}) 5.8-11.2 \mathrm{vs} 24.2 \%, 95 \% \mathrm{Cl}$ 16.0-32.4) and lower effect size than the Total Heart Beat Index (THBI; 0.16 vs 0.26). The PCCl also had the best responsiveness results on all statistical tests. The $\mathrm{PCCl}$ correlation was the largest $(r=0.63, P<0.01,95 \% \mathrm{Cl} 0.43-0.83$, followed by $\mathrm{PCl}(r=0.53$, $P<0.01,95 \% \mathrm{Cl} 0.34-0.72)$ and then the THBI $(r=0.50, P<0.01,95 \% \mathrm{Cl} 0.29-0.71)$.

Conclusions: All three indexes were reproducible and responsive. However, the PCCl gave better statistical results. This index may be useful in functional diagnosis and follow-up of rehabilitation.

Spinal Cord (2014) 52, 683-688; doi:10.1038/sc.2014.108; published online 8 July 2014

\section{INTRODUCTION}

Wheelchairs are the main method of locomotion by individuals with spinal cord injury (SCI) and are used by about 40 million in the United States of America. ${ }^{1-3}$ Clinical practice has shown the need for estimation of energy expenditure during wheelchair propulsion. ${ }^{2}$ In addition to reflecting the functional independence of patients, such estimations allow longitudinal assessment of the necessary adaptations and mobility aids, the patient's physical fitness and the appropriate training schedule.

Energy expenditure can be measured indirectly by oxygen uptake $\left(\mathrm{VO}_{2}\right)$; however, the high cost and limited practicality of this method prevent its routine use. However, the heart rate (HR) has a good correlation with $\mathrm{VO}_{2}$ at submaximal exercise and can be used to determine the energy demand, ${ }^{4,5}$ including for patients with SCI. ${ }^{6}$ However, use of HR alone is not sufficient to measure energy efficiency. To estimate oxygen cost in wheelchair locomotion, there must be a combination of these metabolic parameters with performance measures such as energy expenditure indexes. Using the $\mathrm{HR}$, speed and distance traveled, various indexes, including the Physiological Cost Index (PCI), ${ }^{7}$ Total Heart Beat Index (THBI) ${ }^{8}$ and Propulsion Cardiac Cost Index (PCCI), ${ }^{9}$ have been proposed for performance evaluation in wheelchair propulsion and walking. However, there are lack of studies of these indexes during wheelchair propulsion and this is why this study was critically important to investigate the reproducibility and responsiveness of HR indexes in individuals with SCI.

The present study aimed to determine the reproducibility and responsiveness of HR indexes for measurement of wheeling efficiency during wheelchair locomotion in adults with SCI. The hypothesis was that the levels of reproducibility and responsiveness would be sufficient for evaluating the performance of adults with SCI during wheelchair propulsion.

\section{MATERIALS AND METHODS \\ Ethics approval}

The study was approved by the ethics committee of the Sarah Network of Rehabilitation Hospitals and all patients provided informed written consent to participate in the study.

\section{Participants}

In total, 35 men with SCI were consecutively enrolled in the study. They were participants in the rehabilitation program of the Sarah Network of Rehabilitation Hospitals-North Lake Unit (Brasilia, Brazil). The data collection period was July 2008 to February 2009.

Exclusion criteria were inability to participate in rehabilitation program; presence of cardiovascular, cardiac or orthopedic surgery that would restrict 
performance of wheelchair locomotion; history of metabolic disorders; or presence of medication affecting HR.

Impairment level varied from C6 to L2 (ASIA Impairment Scale A, B, C or D). ${ }^{10}$ When motor injury levels between the two sides of the body were different, the most cranial injury was used. Subjects were stratified into three groups for analysis: tetraplegia (TP; C6-C8), high paraplegia (HP; T1-T6) and low paraplegia (LP; T7-L2). Physical activity was classified as sedentary (no physical activity routine) or active (physical activity performed at least three times a week), regardless of any time devoted to physical therapy or activities of daily living. ${ }^{11}$

\section{Procedures}

Patients were instructed to refrain from eating or smoking for $3 \mathrm{~h}$ before the tests, not to perform strenuous exercise for $6 \mathrm{~h}$ and to empty the bladder before the tests. Women underwent testing after menstruation period. Each participant used the same wheelchair (either the hospital wheelchair or their own), in all test sessions (T0, T1, T2 and T3). Tyres were calibrated as indicated by the manufacturer. Adaptations of wheel rims and gloves were allowed to match the patient's usual conditions of propulsion. Previously collected measures included body mass, arm length and wheelchair weight. After all adjustments, participants were given sufficient time to become familiar with the equipment, before collection of physiological variables. Tests were started only when the patterns of $\mathrm{HR}$ and $\mathrm{VO}_{2}$ were not different from those at rest.

Table 1 Energy expenditure indexes calculation

\begin{tabular}{ll}
\hline Indexes & Formula \\
\hline Physiological Cost Index $(\mathrm{PCI})^{\mathrm{a}}(7)$ & $\frac{\text { Mean propulsion } \mathrm{HR}-\text { mean basal } \mathrm{HR}}{\text { Speed }}=$ beats per meter \\
Total Heart Beat Index $(\mathrm{THBI})^{\mathrm{b}}(8)$ & $\frac{\text { Total heart beats in propulsion }}{\text { Distance }}=$ beats per meter \\
Propulsion Cardiac Cost & $\frac{\text { Mean propulsion } \mathrm{HR}}{\text { Speed }}=$ beats per meter \\
Index $(\mathrm{PCCl})^{\mathrm{C}}(9)$ &
\end{tabular}

aMean heart rates (HR) obtained from the last 3 min, either at rest (basal) or in wheelchair propulsion.

${ }^{b}$ It was considered the totality of all heartbeats recorded during wheelchair propulsion.

'The mean heart rate of all time exercises.
The test protocol consisted of the patient propelling the wheelchair at a comfortable speed for $5 \mathrm{~min}$ around a circular track of $41 \mathrm{~m}$ in length with a level, hard and smooth surface. The course direction was chosen by the participants; however, they were advised to keep the dominant (stronger) arm to the outside of the track to make propulsion easier. Oxygen uptake $\left(\mathrm{VO}_{2}\right)$ was measured using a portable gas analyzer (Cosmed $\mathrm{K} 4 \mathrm{~b} 2$ ) capable of measuring oxygen and $\mathrm{CO}_{2}$ consumption, breath by breath. $\mathrm{HR}$ was

\section{Table 2 Subject demographics}

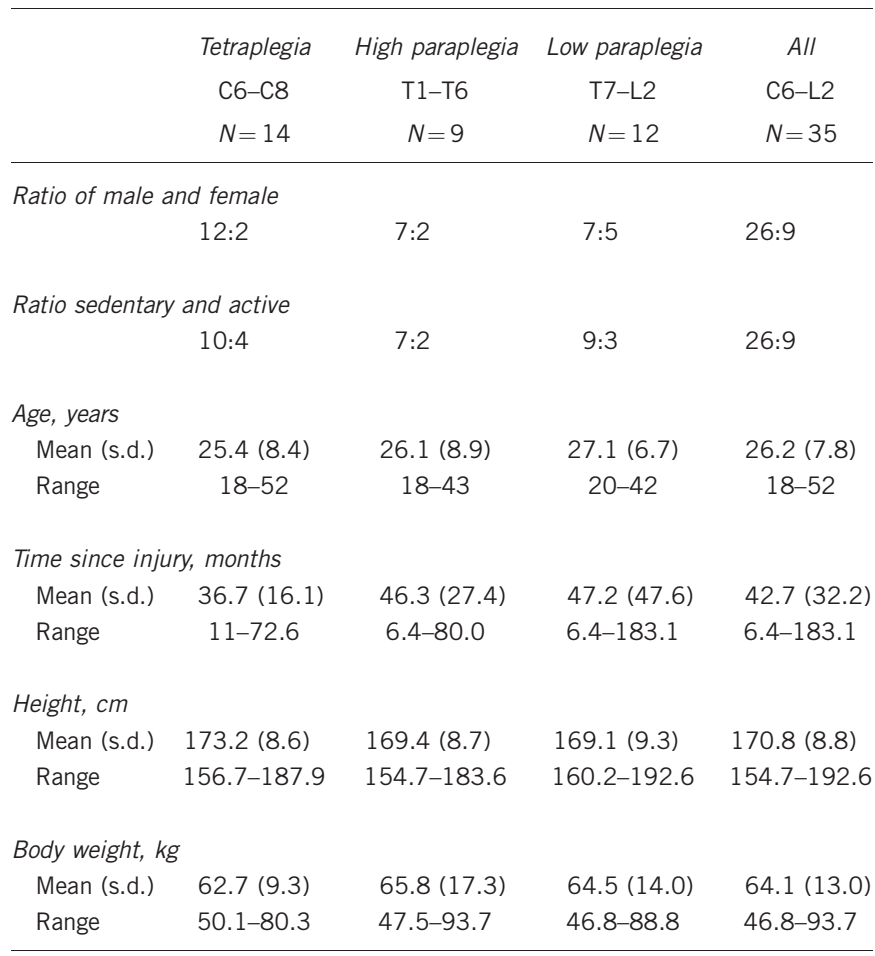

Table 3 Mean values of speed, Borg scale, heart rate, $\mathrm{VO}_{2}$ and $\mathrm{O}_{2}$ cost for tetraplegia (C6-C8), high paraplegia (T1-T6) and low paraplegia (T7-L2) groups in all tests

\begin{tabular}{|c|c|c|c|c|c|c|c|c|c|c|c|c|c|c|c|c|c|c|c|c|}
\hline & \multicolumn{4}{|c|}{ Speed $\left(\mathrm{m} \mathrm{min}^{-1}\right)$} & \multicolumn{4}{|c|}{ Borg Scale (0-10) } & \multicolumn{4}{|c|}{$H R(b p m)$} & \multicolumn{4}{|c|}{$\mathrm{VO}_{2}\left(\mathrm{ml} \mathrm{kg}^{-1} \mathrm{~min}^{-1}\right)$} & \multicolumn{4}{|c|}{$\mathrm{O}_{2} \operatorname{cost}\left(\mathrm{m} / \mathrm{kg}^{-1} \mathrm{~m}^{-1}\right)$} \\
\hline & TO & $T 1$ & T2 & T3 & TO & $T 1$ & T2 & T3 & TO & $T 1$ & T2 & T3 & TO & $T 1$ & $T 2$ & T3 & TO & $T 1$ & T2 & T3 \\
\hline \multicolumn{21}{|l|}{ C6-C8 } \\
\hline Mean & $52.9^{c}$ & $52.0^{c}$ & $49.0^{c}$ & 52.9 & 2.6 & $3.2^{\mathrm{a}}$ & $3.4^{\mathrm{a}}$ & 2.4 & 107 & 112 & 109 & 108 & 6.97 & 7.17 & 7.41 & 6.81 & 0.13 & $0.14^{b}$ & $0.15^{a}$ & 0.13 \\
\hline s.d. & 14.2 & 16.0 & 14.3 & 13.8 & 1.2 & 1.5 & 1.1 & 0.8 & 19 & 18 & 18 & 16 & 3.40 & 3.20 & 3.32 & 2.36 & 0.05 & 0.05 & 0.06 & 0.04 \\
\hline \multicolumn{21}{|l|}{ T1-T6 } \\
\hline Mean & $58.4^{c}$ & $57.2^{c}$ & $55.7^{c}$ & 67.8 & 2.4 & 3.7 & 3.7 & 2.4 & 118 & 121 & 123 & 115 & 7.77 & 8.11 & $8.47^{a}$ & 7.31 & 0.12 & 0.13 & $0.14^{a}$ & 0.11 \\
\hline s.d. & 7.3 & 7.7 & 9.3 & 13.0 & 0.9 & 1.4 & 1.6 & 1.0 & 22 & 23 & 24 & 17 & 3.04 & 2.49 & 2.75 & 2.03 & 0.03 & 0.04 & 0.05 & 0.02 \\
\hline \multicolumn{21}{|l|}{$T 7-L 2$} \\
\hline Mean & 75.9 & 74.8 & 73.5 & 78.7 & 1.9 & 2.7 & 3.4 & 2.1 & 115 & 118 & 123 & 119 & 8.32 & 8.90 & 9.45 & 10.93 & 0.12 & $0.13^{b}$ & $0.14^{a}$ & 0.13 \\
\hline s.d. & 12.6 & 12.2 & 13.0 & 15.2 & 0.5 & 0.7 & 1.1 & 1.1 & 23 & 27 & 27 & 23 & 3.22 & 3.63 & 4.57 & 4.57 & 0.03 & 0.03 & 0.04 & 0.03 \\
\hline \multicolumn{21}{|l|}{$A / l$} \\
\hline Mean & 62.2 & 61.2 & 59.1 & $64.1^{a}$ & 2.3 & $3.1^{\mathrm{a}}$ & $3.5^{a}$ & 2.3 & 112 & 116 & 117 & 113 & 7.42 & 7.85 & 8.21 & 8.17 & 0.12 & $0.13^{a, b}$ & $0.15^{a}$ & 0.13 \\
\hline s.d. & 15.7 & 16.3 & 16.5 & 17.7 & 1.0 & 1.3 & 1.2 & 0.9 & 21 & 22 & 23 & 19 & 2.95 & 3.07 & 3.55 & 3.54 & 0.04 & 0.04 & 0.05 & 0.03 \\
\hline
\end{tabular}

Abbreviation: $\mathrm{HR}$, heart rate.

asignificant difference $(P<0.05)$ compared with T0 test.

bsignificant difference $(P<0.05)$ compared with T2 test.

'Significant difference $(P<0.05)$ compared with T7-L2 group. 

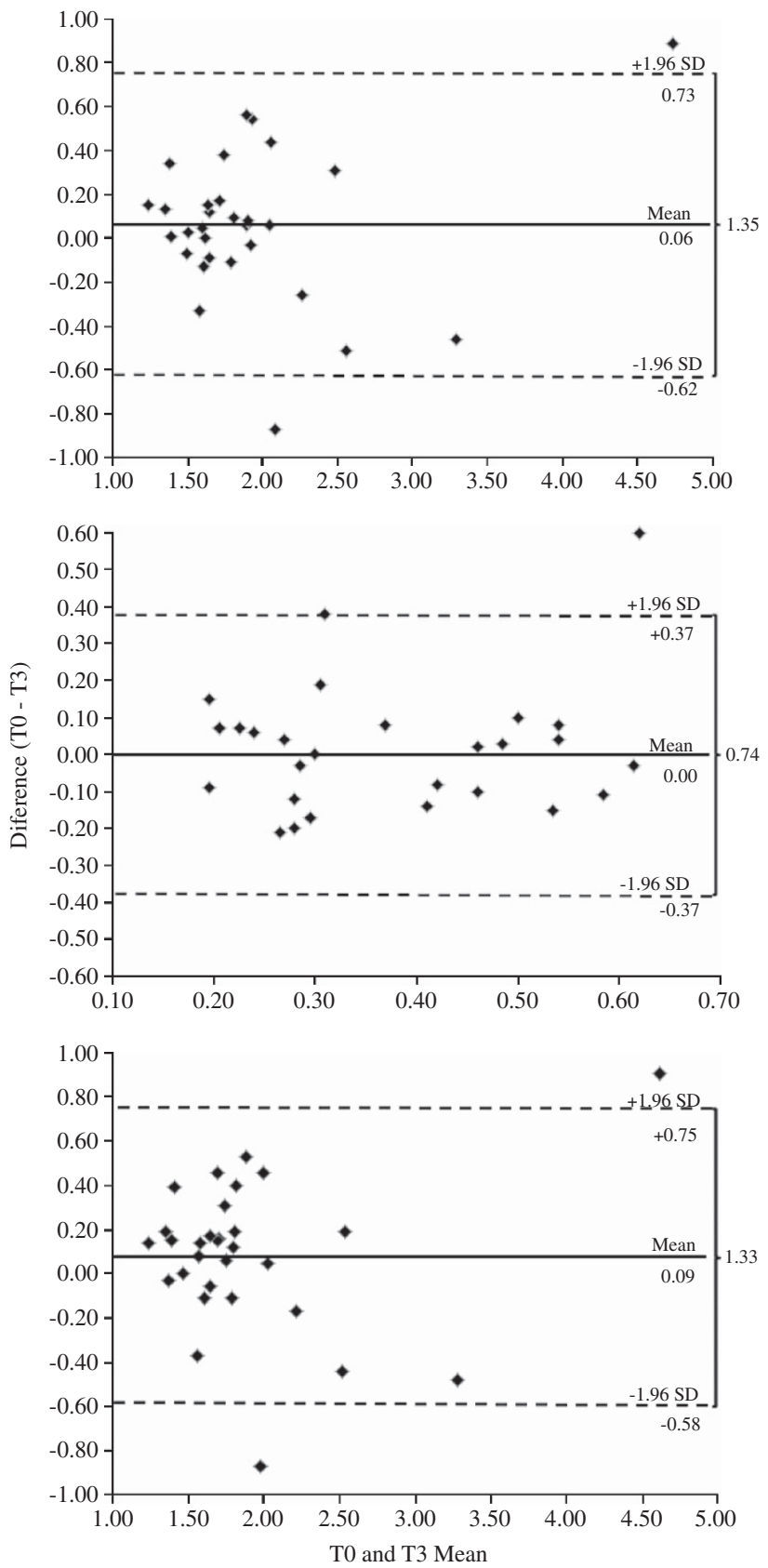

Figure 1 Bland and Altman method comparing TO and T3 tests with THBI, $\mathrm{PCCl}$ and $\mathrm{PCl}$.

monitored using a portable HR monitor (Polar S810), set to capture the interbeat $(\mathrm{R}-\mathrm{R})$ intervals every $5 \mathrm{~s}$ during all procedures. The average values of the variables for the calculation were obtained during the last $3 \mathrm{~min}$ of both the rest and exercise phases. At the end of each test, the rating of perceived exertion was assessed by the Borg scale $(0-10) .{ }^{12,13}$ Total distance was recorded as number of laps multiplied by track perimeter. Propulsion speed was calculated by dividing the distance traveled during the $5 \mathrm{~min}$ of the test. The calculations of energy expenditure indexes are shown in Table 1.

To study reproducibility and responsiveness, we used a test-retest design. Patients were examined at the same time on two separate days during a study period of 5-10 days. On the first day, each subject performed the protocol three times to evaluate responsiveness: the first time at a baseline total weight (patient plus wheelchair; T0), and then with an increase of $10 \%$ (T1) and $20 \%$ (T2) in the total weight. The order of T1 and T2 was randomized, as the weight influences the energy expenditure, ${ }^{3,14-17}$ and the patient was blinded to the weight added. This added load on the wheelchair was divided between the rear $(60 \%)$ and front $(40 \%)$ axles. Patients rested for 7 min between tests to allow the metabolic variables to return to baseline. The last session (T3) was performed only once and on a different day, and was carried out without additional weight, that is, under the same conditions as at baseline (T0), to evaluate the reproducibility of the results.

\section{Statistical analysis}

The Shapiro-Wilks normality test was used to assess the distribution of variables because the sample was less than 50 . The main variables demonstrated a normal distribution $(P>0.05)$.

To assess reproducibility of the indexes for all patients during the baseline test (T0) and retest (T3), we used the paired $t$-test, coefficient of variation, intraclass correlation coefficient, effect size and Bland and Altman method. Effect size was classified by Cohen's ${ }^{18}$ benchmarks: a value of 0.20 or lower represents a change of approximately one-fifth of the baseline s.d. and is considered small; a value of 0.50 reflects a change of at least half the baseline s.d. and is considered moderate; and a value of 0.80 or greater represents a change of at least four-fifth of the baseline s.d. and is viewed as large.

Responsiveness of indexes for all patients was categorized as internal or external. The first characterizes the ability of a measure to change over a prespecified time frame, and the second reflects the extent to which the change in a measure relates to a corresponding change in a reference measure of clinical or health status. ${ }^{19}$ For internal responsiveness, we used analysis of variance for repeated measures with the Bonferroni post hoc test $(P<0.05)$ to compare T0, T1 and T2, and the mean Pearson correlation for each patient to analyze the differences between indexes and the 0, 10 and 20\% loads. For external responsiveness, the mean Pearson for each patient was used to analyze the correlation between the indexes and the oxygen cost (the gold standard).

The statistical packages used for data processing were Statview for Windows (version 5.0.1; SAS Institute Inc, Cary, NC, USA), SPSS (version 13.0; SPSS Inc) and MedCalc (version 9.0.1.0; MedCalc). In the absence of multiple comparisons, statistical significance was set at $P<0.05$ (two-tailed).

\section{RESULTS}

There were no significant differences in anthropometric or clinical variables between groups (Table 2). All 35 patients attended the first day of testing (T0, T1 and T2); however, five did not attend for retesting (T3) because of health problems.

\section{Reproducibility}

Speed, oxygen cost, oxygen uptake $\left(\mathrm{VO}_{2}\right)$ and Borg scale did not change between the baseline test (T0) and the retest (T3) in the stratified groups. When all subjects were considered, only the speed of propulsion was significantly different between T0 and T3 (Table 3).

The paired $t$-test also showed no difference between the means of the indexes at T0 and T3 for the groups overall and for each group individually. The HP group had lower significant values for the PCCI and THBI compared with the TP and LP groups (Table 4).

The coefficient of variation was less than $10 \%$ for both the PCCI and THBI, whereas that for the PCI was $24.2 \%$. The intraclass coefficient was positive for all indexes and was significantly different between T0 and T3 $(P<0.05)$, particularly for the PCCI $(0.878)$ and THBI (0.875). The effect size for both the PCCI and PCI showed no effect, that is, exhibited values of less than 0.20 , whereas that for the THBI was considered a small effect, as it was between 0.20 and 0.30 (Table 5).

Using the Bland and Altman method, the difference between the means was low and the intervals around these differences $( \pm 1.96$ times the s.d.) were small for all three indexes. Only two points were outside these limits (Figure 1). 
Table $4 \mathrm{PCCl}, \mathrm{PCl}$ and THBI mean values for tetraplegia (C6-C8), high paraplegia (T1-T6) and low paraplegia (T7-L2) groups in all tests

\begin{tabular}{|c|c|c|c|c|c|c|c|c|c|c|c|c|}
\hline & \multicolumn{4}{|c|}{$\mathrm{PCCl}$} & \multicolumn{4}{|c|}{$\mathrm{PCl}$} & \multicolumn{4}{|c|}{$T H B I$} \\
\hline & TO & $T 1$ & $T 2$ & $T 3$ & TO & $T 1$ & $T 2$ & $T 3$ & TO & $T 1$ & $T 2$ & $T 3$ \\
\hline \multicolumn{13}{|l|}{ C6-C8 } \\
\hline Mean & 2.27 & 2.44 & 2.48 & 2.23 & 0.53 & 0.71 & 0.72 & 0.53 & 2.24 & 2.37 & 2.42 & 2.19 \\
\hline s.d. & 0.93 & 0.88 & 0.81 & 0.84 & 0.27 & 0.28 & 0.22 & 0.31 & 0.91 & 0.89 & 0.76 & 0.83 \\
\hline \multicolumn{13}{|l|}{ T1-T6 } \\
\hline Mean & 1.95 & 2.03 & $2.13^{a}$ & 1.71 & 0.45 & 0.59 & 0.55 & 0.35 & 1.93 & $1.98^{b}$ & $2.10^{\mathrm{a}}$ & 1.62 \\
\hline s.d. & 0.38 & 0.34 & 0.42 & 0.14 & 0.27 & 0.29 & 0.29 & 0.18 & 0.36 & 0.32 & 0.38 & 0.11 \\
\hline \multicolumn{13}{|l|}{$T 7-L 2$} \\
\hline Mean & $1.53^{c, d}$ & $1.60^{a, b, c, d}$ & $1.70^{a, c}$ & $1.52^{\mathrm{c}}$ & 0.32 & $0.33^{b, c}$ & $0.41^{a, c}$ & 0.33 & $1.53^{\mathrm{c}, \mathrm{d}}$ & $1.61^{a, b, c, d}$ & $1.69^{\mathrm{a}, \mathrm{c}, \mathrm{d}}$ & $1.49^{c}$ \\
\hline s.d. & 0.20 & 0.23 & 0.26 & 0.22 & 0.12 & 0.12 & 0.13 & 0.09 & 0.19 & 0.22 & 0.26 & 0.23 \\
\hline \multicolumn{13}{|l|}{ All } \\
\hline Mean & 1.94 & $2.05^{a, b}$ & $2.13^{a}$ & 1.90 & 0.44 & $0.55^{\mathrm{a}}$ & $0.57^{a}$ & 0.43 & 1.91 & $2.01^{a, b}$ & $2.09^{a}$ & 1.85 \\
\hline s.d. & 0.69 & 0.69 & 0.66 & 0.67 & 0.24 & 0.29 & 0.25 & 0.25 & 0.67 & 0.67 & 0.62 & 0.66 \\
\hline
\end{tabular}

Abbreviations: PCCI, Propulsion Cardiac Cost Index; PCI, Physiological Cost Index; TBHI, Total Heart Beat Index.

asignificant difference $(P<0.05)$ compared with TO test.

a Significant difference $(P<0.05)$ compared with T0 test.
bSignificant difference $(P<0.05)$ compared with T2 test.

'Significant difference $(P<0.05)$ compared with 12 test.
cSicant difference $(P<0.05)$ compared with $66-C 8$ groups.

dSignificant difference $(P<0.05)$ compared with T1-T6 groups.

Table 5 Reproducibility statistic results for T0, and $\mathrm{T} 3$ tests to $\mathrm{PCCl}, \mathrm{PCI}$ and $\mathrm{THBI}$

\begin{tabular}{|c|c|c|c|c|c|c|c|c|c|}
\hline & \multicolumn{3}{|c|}{$\mathrm{PCCl}$} & \multicolumn{3}{|c|}{$\mathrm{PCl}$} & \multicolumn{3}{|c|}{$T H B I$} \\
\hline & Value & $95 \% \mathrm{Cl}$ & $\mathrm{P}$-value & Value & $95 \% \mathrm{Cl}$ & P-value & Value & $95 \% \mathrm{Cl}$ & P-value \\
\hline Mean difference (paired $t$-test) & -0.057 & $-0.717-0.185$ & 0.374 & 0.000 & $-0.071-0.070$ & 0.992 & -0.087 & $-0.040-0.214$ & 0.172 \\
\hline $\begin{array}{l}\text { Coefficient of } \\
\text { variation (\%) }\end{array}$ & 8.5 & 5.8-11.2 & - & 24.2 & 16.0-32.4 & - & 9.5 & 6.9-12.2 & - \\
\hline $\begin{array}{l}\text { Intraclass Correlation Coefficient } \\
\text { (ICC) }\end{array}$ & 0.878 & $0.759-0.940$ & $<0.05$ & 0.682 & $0.431-0.835$ & $<0.05$ & 0.875 & $0.755-0.939$ & $<0.05$ \\
\hline Effect size & 0.16 & - & - & 0.00 & - & - & 0.26 & - & - \\
\hline Bland and Altman method ${ }^{\mathrm{b}}$ & 0.06 & $\begin{array}{c}0.73 \text { to }-0.62 \\
\Delta=1.35\end{array}$ & - & 0.00 & $\begin{array}{c}0.37 \text { to }-0.37 \\
\Delta=0.74\end{array}$ & - & 0.09 & $\begin{array}{c}0.75 \text { to }-0.58 \\
\Delta=1.33\end{array}$ & \\
\hline
\end{tabular}

Abbreviations: $\mathrm{Cl}$, confidence interval; $\mathrm{PCCl}$, Propulsion Cardiac Cost Index; PCI, Physiological Cost Index, TBHI, Total Heart Beat Index.

apaired $t$-test value is given by means difference (T3-TO).

${ }^{b}$ Bland and Altman Method: value is equal to means difference. Indicated range is mean difference plus/less 196 times s.d., not $95 \% \mathrm{Cl}$.

\section{Responsiveness}

Although not significant, the speed of propulsion reduced progressively in T0, T1 and T2 within each group. The LP group had the highest average propulsion speed in each investigated test $(P<0.05)$. The Borg effort perception value increased between the T0 and the T1/T2 tests $(P<0.05)$ for the TP group, indicating increased effort with higher workload. Oxygen cost also increased progressively with higher load for all groups and, in the TP and LP groups, the T2 test differed significantly from T0 and T1 $(P<0.05)$. In the HP group, there was a significant difference only between T0 and T2 $(P<0.05)$. Similar to the oxygen cost, the mean $\mathrm{VO}_{2}$ increased in each test. However, there was a significant difference only between the T0 and T2 tests in the HP group $(P<0.05)$. There were no intergroup or intragroup differences in HR (Table 3 ).

The TP group showed no differences in indexes between the T0, T1 and T2 tests. In the HP group, the PCCI increased significantly between T0 and T2, and the THBI between T2 and both T0 and T1.
The LP group showed a difference for all three indexes $(P<0.05)$, except for the comparison of T0 and T1 for the PCI (Table 4). When the three groups were compared, the LP group had significantly lower index values compared with the other two groups (Table 4).

There were significant positive correlations for the 0,10 and $20 \%$ load increments for each individual $(P<0.05)$, in both external (indexes $\times$ oxygen cost) and internal (indexes $\times$ loads) responsiveness. Differences between T0 with 10 and $20 \%$ added load were incremental and significant $(P<0.05$; Table 6).

\section{DISCUSSION}

This study evaluated the reproducibility and responsiveness of three HR indexes in patients with SCI during wheelchair propulsion. All indexes were reproducible and responsive, with PCCI having the largest set of features with these favorable properties. 
Table 6 Responsiveness statistic results for T0, T1 and T2 tests to PCCI, PCI and THBI

\begin{tabular}{|c|c|c|c|c|c|c|c|c|c|}
\hline & \multicolumn{3}{|c|}{$\mathrm{PCCl}$} & \multicolumn{3}{|c|}{$\mathrm{PCl}$} & \multicolumn{3}{|c|}{$T H B I$} \\
\hline & Value & $95 \% \mathrm{Cl}$ & P-value & Value & $95 \% \mathrm{Cl}$ & P-value & Value & $95 \% \mathrm{Cl}$ & P-value \\
\hline Pearson ${ }^{a}$ & 0.63 & $0.434-0.826$ & $<0.05$ & 0.53 & $0.341-0.719$ & $<0.05$ & 0.50 & $0.294-0.706$ & $<0.05$ \\
\hline \multicolumn{10}{|c|}{ Internal responsiveness } \\
\hline \multicolumn{10}{|l|}{ ANOVAC } \\
\hline T0-T1 & - & -0.168 to -0.047 & $<0.05$ & - & -0.186 to -0.052 & $<0.05$ & - & -0.143 to -0.030 & $<0.05$ \\
\hline T1-T2 & - & -0.118 to -0.041 & $<0.05$ & - & -0.072 to 0.017 & $0.218^{d}$ & - & -0.136 to -0.038 & $<0.05$ \\
\hline T0-T2 & - & -0.255 to -0.119 & $<0.05$ & - & -0.210 to -0.083 & $<0.05$ & - & -0.248 to -0.099 & $<0.05$ \\
\hline
\end{tabular}

Abbreviations: ANOVA, analysis of variance; Cl, confidence interval; PCCI, Propulsion Cardiac Cost Index; PCI, Physiological Cost Index, TBHI, Total Heart Beat Index.

aThe mean of correlation for each patient between Indexes and $\mathrm{O}_{2}$ cost (external responsiveness). $95 \% \mathrm{Cl}$ refers to the mean of correlation. $P$-value was obtained by correlation of index means with cost $\mathrm{O}_{2}$ values for TO, T1 and T2 tests.

${ }^{b}$ The mean of correlation for each patient between indexes and 0, 10 and $20 \%$ loads (internal responsiveness). $95 \% \mathrm{Cl}$ refers to the mean of correlation. $95 \% \mathrm{Cl}$ refers to the mean of correlation. $P$-value was obtained by correlation of indexes means with 0,10 and $20 \%$ loads for T0, T1 and T2 tests.

cBonferroni post hoc: $P<0.05$.

${ }^{\mathrm{d}}$ No statistical difference: no responsiveness between T1 and T2 tests.

\section{Reproducibility}

Results for secondary outcomes, $\mathrm{VO}_{2}$, oxygen cost, perceptive Borg scale, HR and speed propulsion behaved as expected in tests of reproducibility and did not vary between tests and retests. This indicates that the influence of any individual variable in the main outcome was minimal.

Indexes based on HR are widely used in gait rehabilitation ${ }^{8,9,20}$ and are increasingly used in measurement of wheelchair ${ }^{2,8,17}$ or handcycle ${ }^{2,4,21-24}$ propulsion. However, the reproducibility of these indexes in wheelchair propulsion in patients with SCI has not yet been determined.

Indexes have advantages in terms of their practicality in use, and measurement of HR in relation to the average speed of propulsion (efficiency measure) is easy to monitor. Thus, it is possible to obtain a more accurate assessment of performance to verify, for example, the response to training or even the physical capacity of an individual. In the particular case of SCI, individual correlations between HR and $\mathrm{VO}_{2}$ are necessary, making the traditional use of $\mathrm{HR}$ inaccurate for these situations. ${ }^{25}$ Similarly, indexes should be used at submaximal speeds. $^{2,4,8,21-24}$

TP, HP and LP showed decreasing values for the mean of the three indexes in the first test (T0), and these results were consistent with the type of injury impairment in each group. It is known that patients with TP require more energy than patients with paraplegia to perform the same activity. ${ }^{26}$ Despite the speed being significantly lower in the TP group, the perceived exertion and the mean HR were equivalent to the other two groups. Higher-placed lesions have a greater effect on the autonomic nervous system, and the lower muscle mass of such patients means that daily activities require a higher energy cost from this population. ${ }^{26}$

Although the three indexes were evaluated as reproducible, we found that the PCCI gave a better performance than the other two. The PCCI also has another advantage in that the mean HR that is used in its calculation is easily obtained using the HR monitors currently in use.

\section{Responsiveness}

The responsiveness of any one variable is related to the changes caused by an offered stimuli. ${ }^{27}$ The responsiveness of the metabolic variables in wheelchair propulsion in patients with SCI has been evaluated in several ways. $8,17,23,28$ However, we could not find any publication that systematically evaluated these indexes based on HR responsiveness in wheelchair propulsion. ${ }^{4,5,8,21-23,28}$

Several reports from India used the PCI to assess the effect of interventions in patients with SCI. The PCI was used to infer oxygen cost at different speeds in patients using an arm crank and a wheelchair, to compare the physiological responses between the same means of locomotion, as well as between single-arm and dual-arm propulsion, and, finally, to investigate the longitudinal response after training at a comfortable speed. ${ }^{4,21-23}$ In order to evaluate energy cost, another study used the PCI to compare two types of wheels during wheelchair propulsion in a circuit of daily living activities. ${ }^{17}$ Other authors have used the THBI to estimate the energy cost in rehabilitation, when comparing patients with SCI during wheelchair propulsion and walking using orthoses. ${ }^{8}$

In our study, responsiveness was analyzed by the random increase in total load by 10 and $20 \%$. All indexes were characterized as responsive, with minor differences between them. The best performance was obtained with the PCCI.

\section{Study limitations}

There are several limitations to our study. A larger number of participants could have increased the consistency of results, as a small sample size increases the chance of incurring a type II error, that is, of finding false equalities.

The mechanical efficiency of propulsion depends on the patient's ability to use a wheelchair, and this ability is lower in newly injured patients. ${ }^{3}$ Although we recorded the time since injury, this did not always coincide with the length of wheelchair use. Moreover, differences between types of wheelchair also influence performance and energy expenditure. ${ }^{3}$ In this protocol, we did not standardize the wheelchair type, as we were aiming for greater external validity. Of the 35 patients, 7 used a hospital wheelchair in all the tests, and 10 used a folding wheelchair. Therefore, we cannot affirm whether the selected activity performed only once in this study can be sufficient for examining the reliability to estimate the energy expenditure utilizing the HR indexes. 
SCI impairment is another aspect open to question in the TP and HP groups. According to ASIA, only injuries classified as ASIA Impairment Scale grade A are considered 'complete'. In the current study, $54 \%(19 / 35)$ of the participants were classified as having incomplete SCI. Therefore, there is doubt about the strength of the intact nerve fibers in the autonomic nervous system in these ratings, which directly influence the HR.

Finally, during the 7 months of data collection, climatic changes such as humidity and temperature could have affected the performance of patients during wheelchair propulsion. It is also known that individuals respond physiologically differently according to their biological rhythms.

\section{CONCLUSION}

All three indexes showed good reproducibility and responsiveness; however, the PCCI had better performance and simpler calculation, which facilitates its routine clinical use. All three indexes showed good correlation with $\mathrm{VO}_{2}$ at all SCI levels. In addition, the indexes were able to evaluate the differences between groups with different SCI impairments. Thus, these indexes can be used appropriately in clinical practice. The current study opens new prospects for research, expanding the search for common situations of clinical practice and physical education.

\section{DATA ARCHIVING}

There were no data to deposit.

\section{CONFLICT OF INTEREST}

The authors declare no conflict of interest.

\section{ACKNOWLEDGEMENTS}

We certify that no party having a direct interest in the results of the research supporting this article has or will confer a benefit on us or on any organization with which we are associated.

1 Spinal cord injury Facts and figures at a glance. J Spinal Cord Med 2008; 31 357-358.

2 Mukherjee G, Bhowmik P, Samanta A. Effect of chronic use of different propulsion systems in wheelchair design on the aerobic capacity of Indian users. Indian J Med Res 2005: 121: 747-758.

3 van der Woude LH, de Groot S, Janssen TW. Manual wheelchairs: research and innovation in rehabilitation, sports, daily life and health. Med Eng Phys 2006; 28 : 905-915.

4 Mukherjee G, Samanta A. Evaluation of ambulatory performance of the arm propelled three-wheeled chair using heart rate as a control index. Disabil Rehabil 2000; 22: 464-470.

5 Sawatzky BJ, Miller WC, Denison I. Measuring energy expenditure using heart rate to assess the effects of wheelchair tyre pressure. Clin Rehabil 2005; 19: 182-187.
6 Valent LJ, Dallmeijer AJ, Houdijk H, Slootman J, Janssen TWJ, Hollander AP et al. The individual relationship between heart rate and oxygen uptake in people with a tetraplegia during exercise. Spinal Cord 2007; 45: 104-111.

7 MacGregor J. The evaluation of patient performance using long-term ambulatory monitoring technique in the domiciliary environment. Physiotherapy 1981; 67: 30-33

8 Hood VL, Granat MH, Maxwell DJ, Hasler JP. A new method of using heart rate to represent energy expenditure: the Total Heart Beat Index. Arch Phys Med Rehabil 2002; 83: 1266-1273.

9 Bernardi M, Macaluso A, Sproviero E, Castellano V, Coratella D, Felici F et al. Cost of walking and locomotor impairment. J Electromyogr Kinesiol 1999; 9: 149-157

10 Marino RJ, Barros T, Biering-Sorensen F, Burns SP, Donovan WH, Graves DE et al. International standards for neurological classification of spinal cord injury. J Spinal Cord Med 2003; 26(Suppl 1), S50-S56.

11 Janssen TW, Dallmeijer AJ, Veeger DJ, van der Woude LH. Normative values and determinants of physical capacity in individuals with spinal cord injury. J Rehabil Res Dev 2002; 39: 29-39.

12 Borg G. A general scale to rate symptoms and feelings related to problems of ergonomic and organizational importance. G Ital Med Lav Ergon 2008; 30(1 Supp A), A8-A10.

13 Borg GA. Psychophysical bases of perceived exertion. Med Sci Sports Exerc 1982; 14 377-381.

14 Beekman CE, Miller-Porter L, Schoneberger M. Energy cost of propulsion in standard and ultralight wheelchairs in people with spinal cord injuries. Phys Ther 1999; 79: $146-158$.

15 Boninger ML, Koontz AM, Sisto SA, Dyson-Hudson TA, Chang M, Price R et al. Pushrim biomechanics and injury prevention in spinal cord injury: recommendations based on CULP-SCI investigations. J Rehabil Re Dev 2005; 42(3 Suppl 1), 9-19.

16 Hilbers PA, White TP. Effects of wheelchair design on metabolic and heart rate responses during propulsion by persons with paraplegia. Phys Ther 1987; 67 1355-1358.

17 Hughes B, Sawatzky BJ, Hol AT. A comparison of spinergy versus standard steel-spoke wheelchair wheels. Arch Phys Med Rehabil 2005; 86: 596-601.

18 Cohen J. Statistical Power Analysis for the Behavioral Sciences, 2nd edn. Lawrence Erlbaum: New Jersey, 1988.

19 Husted JA, Cook RJ, Farewell VT, Gladman DD. Methods for assessing responsiveness a critical review and recommendations. J Clin Epidemiol 2000; 53: 459-468.

20 ljzerman MJ, Nene AV. Feasibility of the physiological cost index as an outcome measure for the assessment of energy expenditure during walking. Arch Phys Med Rehabil 2002; 83: 1777-1782.

21 Mukherjee G, Bhowmik P, Samanta A. Physical fitness training for wheelchair ambulation by the arm crank propulsion technique. Clin Rehabil 2001; 15: 125-132.

22 Mukherjee G, Samanta A. Physiological response to the ambulatory performance of hand-rim and arm-crank propulsion systems. J Rehabil Res Dev 2001; 38 391-399.

23 Mukherjee G, Samanta A. Arm-crank propelled three-wheeled chair: physiological evaluation of the propulsion using one arm and both arm patterns. Int $J$ Rehabil Res 2004; 27: 321-324.

24 Mukherjee G, Samanta A. Energy cost and locomotor performance of the low-cost arm-lever-propelled three-wheeled chair. Int J Rehabil Res 2001; 24: 245-249.

25 Hiilloskorpi H, Fogelholm M, Laukkanen R, Pasanen M, Oja P, Mänttäri A et al. Factors affecting the relation between heart rate and energy expenditure during exercise. Int $\mathrm{J}$ Sports Med 1999; 20: 438-443.

26 Phillips WT, Kiratli BJ, Sarkarati M, Weraarchakul G, Myers J, Franklin BA et al. Effect of spinal cord injury on the heart and cardiovascular fitness. Curr Probl Cardiol 1998 23: $641-716$

27 Stewart MW, Melton-Rogers SL, Morrison S, Figoni SF. The measurement properties of fitness measures and health status for persons with spinal cord injuries. Arch Phys Med Rehabil Apr 2000; 81: 394-400.

28 Rimaud D, Calmels P, Roche F, Mongold JJ, Trudeau F, Devillard X. Effects of graduated compression stockings on cardiovascular and metabolic responses to exercise and exercise recovery in persons with spinal cord injury. Arch Phys Med Rehabil Jun 2007; 88: 703-709. 